\title{
The pathways to manage air pollution: an ontological assessment of the National Clean Air Programme 2019, India
}

\author{
Munikrishnappa Anilkumar, Shwetmala Kashyap*, Susanna G. Mitra, Devina Neogi, \\ Arkalgud Ramaprasad, Anupama Sanjeev, Chetan Singai, S. D. Sreeganga and Nibras K. Thodika
}

The National Clean Air Programme 2019 (NCAP 2019) addresses India's air pollution problem systematically and systemically. Its 198 action points comprehensively encapsulate the recommended pathways of the programme. We present an ontological analysis of these action points and highlight the pathways they emphasize frequently, infrequently and overlook. Subsequently, we discuss the selectivity and segmentation of the pathways in the action points, the gaps in them and the potential gaps in the effectiveness of NCAP 2019. Last, we present recommendations to discover and design novel pathways to bridge the gaps and improve the effectiveness of the programme.

Keywords: Air pollution, action points, ontological analysis, policies and programmes.

ANY system for managing air pollution is complex ${ }^{1}$, and calls for systematic and systemic policies. The air quality in different parts of India is changing due to the increase in population and changes in lifestyle. The consequent air pollution is affecting the health of the population, environment and economy ${ }^{2}$.

Over the past five decades, significant advances in our understanding of air pollution through empirical and theoretical research on social and technical issues have resulted in opportunities to understand and manage the complete system. Such a system should ideally manage the full lifecycle of generation, emission, propagation, filtration, absorption and elimination of air pollution. However, air pollution management has commonly focused on only a part of the problem based on the immediate requirements, thus missing the big picture. The challenge is to address the problem systemically using a comprehensive framework of air pollution management.

Due to the growing threat of air pollution in the country, the Ministry of Environment, Forest and Climate Change, Government of India had proposed the National Clean Air Programme (NCAP) in 2019, which emphasizes mitigation of local and transboundary air pollution. Its action points are expected to reduce the levels of air pollution in Indian cities, as well as regional and rural areas.

Munikrishnappa Anilkumar, Shwetmala Kashyap, Susanna G. Mitra, Devina Neogi, Arkalgud Ramaprasad, Anupama Sanjeev, Chetan Singai, S. D. Sreeganga and Nibras K. Thodika are in the Ramaiah Public Policy Centre, Gokula Education Foundation (Medical), MS Ramaiah Nagar, MSRIT Post, Bengaluru 560 054, India; Arkalgud Ramaprasad is also in the University of Illinois at Chicago, IL 60607, USA.

*For correspondence. (e-mail: shwetmala.kashyap@rppc.ac.in)
It incorporates measures for effective monitoring, assessment and control of air pollution in India. This study presents an ontological assessment of NCAP 2019 and recommends additional pathways to manage air pollution in the country.

\section{Ontology of air pollution management}

Figure 1 shows the ontology of air pollution management. The method of constructing the ontology has been described by Ramaprasad and $\mathrm{Syn}^{3,4}$. It has been applied to the study of mHealth ${ }^{5}$, national education policy ${ }^{6}$, national health policy ${ }^{7}$ and other domains.

Air pollution management can be broadly defined by eight dimensions (level, instrument, impetus, stage, source, location, attribute and impact corresponding to the columns in Figure 1). Each dimension is further defined by a taxonomy of elements. For instance, the dimension 'attribute' has three elements: composition, concentration and toxicity. All the dimensions and elements of the ontology are defined in the Glossary. The objective is to manage the impacts of air pollution listed in the rightmost column of the framework (Figure 1). Air pollution is defined by the stage, source, location and attribute of the pollution that are listed in the fourth to seventh columns of the framework (Figure 1). The management policies themselves are defined by their level, instrumentality $^{8}$, and impetus listed in the first three columns of the framework (Figure 1).

The ontology encapsulates $3,960,000$ pathways for the management of air pollution. Each pathway is a concatenation of an element from the eight columns, left to right, 


\begin{tabular}{|c|c|c|c|c|c|c|c|c|c|c|c|c|c|c|}
\hline \multicolumn{15}{|c|}{ Air Pollution Management Policy } \\
\hline \multicolumn{6}{|c|}{ Management Policy } & \multicolumn{7}{|c|}{$\begin{array}{ll}\text { Air Pollution } \\
\end{array}$} & \multirow{2}{*}{\multicolumn{2}{|c|}{ Impact }} \\
\hline Level & & Instrument & & Impetus & & Stage & & Source & & Location & & Attribute & & \\
\hline $\begin{array}{l}\text { Global } \\
\text { Central } \\
\text { Regional } \\
\text { State } \\
\text { Local }\end{array}$ & $\mp$ & $\begin{array}{l}\text { Legislative } \\
\text { Regulatory } \\
\text { Economic } \\
\text { Fiscal } \\
\text { Contractual } \\
\text { Information } \\
\text { Social } \\
\text { Legal }\end{array}$ & $\Xi$ & $\begin{array}{l}\text { Prohibitive } \\
\text { Restrictive } \\
\text { Normative } \\
\text { Supportive } \\
\text { Generative }\end{array}$ & $\begin{array}{l}\text { 등 } \\
\text { 흥 } \\
\text { 을 }\end{array}$ & $\begin{array}{l}\text { Generation } \\
\text { Emission } \\
\text { Propagation } \\
\text { Filtration } \\
\text { Absorption } \\
\text { Elimination }\end{array}$ & 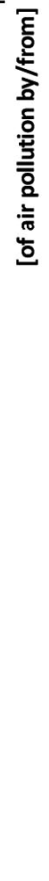 & $\begin{array}{l}\text { Anthropic } \\
\text { Societal } \\
\text { Domestic cooking } \\
\text { Dump yards } \\
\text { Events/festival } \\
\text { Industrial } \\
\text { Construction } \\
\text { Building } \\
\text { Road } \\
\text { Mining/Quarrying } \\
\text { Drilling } \\
\text { Extracting } \\
\text { Blasting } \\
\text { Power generation } \\
\text { Transportation } \\
\text { People } \\
\text { Freight } \\
\text { Other } \\
\text { Agriculture } \\
\text { Farming } \\
\text { Stubble burning } \\
\text { Natural } \\
\text { Forest fires } \\
\text { Seasonal variation } \\
\text { Elevation } \\
\text { Volcanic eruptions } \\
\text { Rock radioactivity } \\
\text { Wind erosion }\end{array}$ & 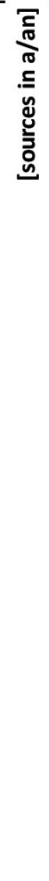 & $\begin{array}{l}\text { Urban } \\
\text { Peri-urban } \\
\text { Rural } \\
\text { Small cities } \\
\text { Large cities }\end{array}$ & 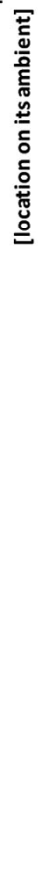 & $\begin{array}{l}\text { Composition } \\
\text { Concentration } \\
\text { Toxicity }\end{array}$ & 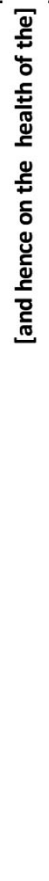 & $\begin{array}{l}\text { Population } \\
\text { Individual } \\
\text { Aged } \\
\text { Adult } \\
\text { Children } \\
\text { Community } \\
\text { Society } \\
\text { Economy } \\
\text { Agriculture } \\
\text { Industry } \\
\text { Environment } \\
\text { Indoor } \\
\text { Outdoor } \\
\text { Locality } \\
\text { Others }\end{array}$ \\
\hline
\end{tabular}

Figure 1. Ontology of air pollution management.

with the adjacent words/phrases. Three illustrative pathways are listed below, with an example from NCAP 2019 (ref. 9).

Section 7.4, Regional and Transboundary Plan of the report on the National Clean Air Program, 2019 lists action points of which the first is "Various measures specially implementation of pollution abatement policies as Transport - Auto fuel policy for stringent norms for fuel and vehicles, road to rail/waterways, fleet modernization, electric vehicle policies, clean fuels, bye passes, taxation policies, etc. Industries stringent industrial standards, clean fuels, clean technology, enforcement (continuous monitoring); and biomass - enhanced LPG penetration, agricultural burning control and management need to emphasized through regional level inter-state coordination specifically for the Indo-Gangetic plain'.

The above section can be mapped to the following three pathways in the ontology:

- Regional legislative restrictive policy on emission from transportation in urban location on its ambient air toxicity and hence on the health of the population.

- Regional fiscal supportive policy on propagation of LPG cylinders for domestic cooking in rural locations on its ambient air composition and hence on the health of the locality.
- Regional regulatory restrictive policy on eliminating agricultural stubble burning in the rural location on its ambient air toxicity and hence on the health of the Indo Gangetic Plain.

The ontology is a systematic, structured natural language representation of air pollution management. We analyse NCAP 2019 through the lens of this ontology.

\section{Method}

The method of analysis is similar to the analysis of the national education health policies cited earlier. In the following, we describe the unit of analysis, coding, monads map, and themes map.

\section{Unit of analysis}

The unit of analysis was each action point in NCAP 2019. The population of 198 action points was coded onto the ontology using an MS Excel tool.

\section{Coding}

Each action point was coded for the presence or absence of each element of the ontology.

The coding was binary: 1 for present, 0 for absent and all the elements were unweighted. In this study both 
GENERAL ARTICLES

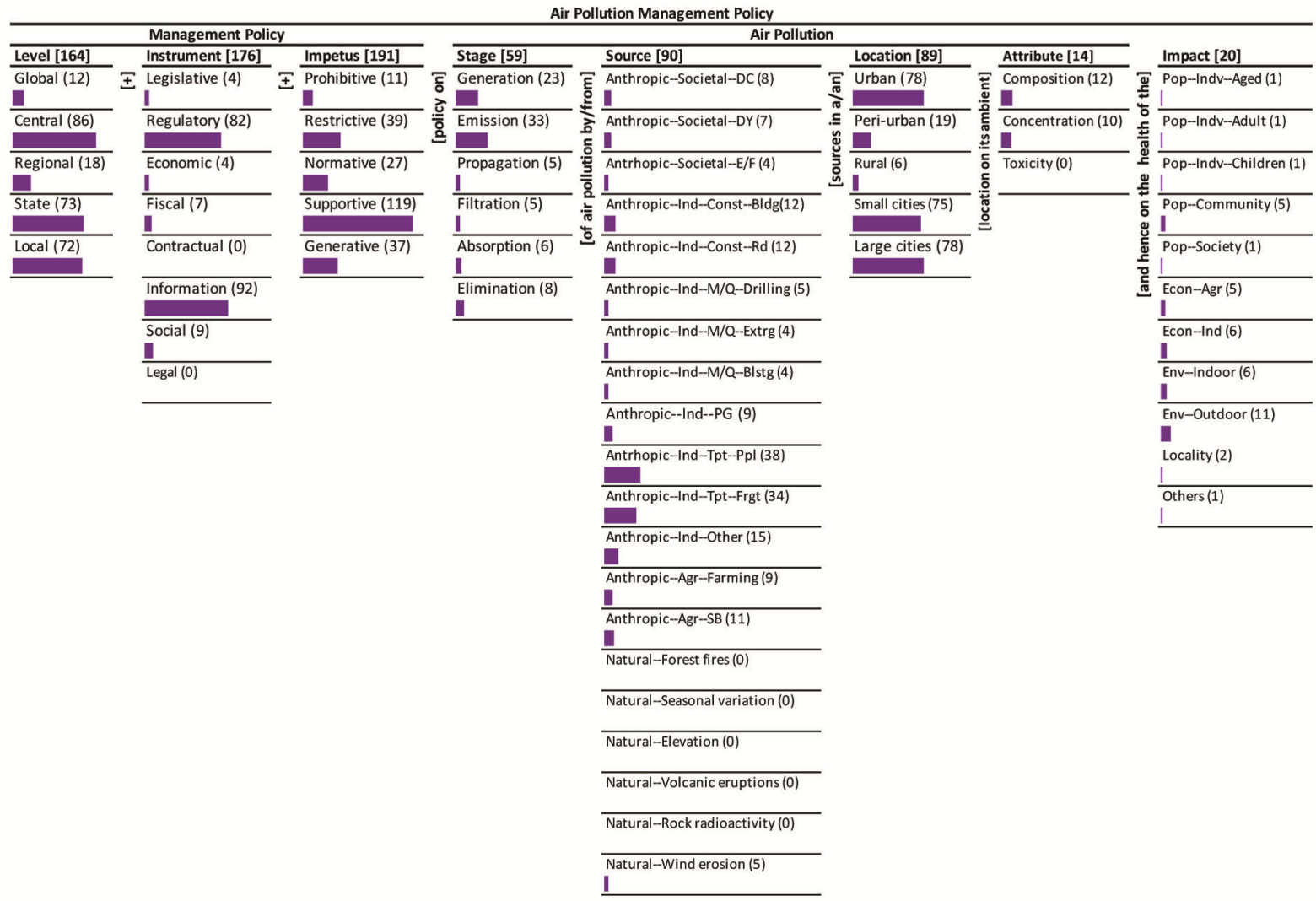

Figure 2. Monads map of NCAP 2019.

present and absent elements are considered to be equally important. An action point was coded for the presence (1) of an element only if it was explicit in the text. The elements not present were coded as being absent (0). Even if an element were present multiple times, it was coded only once for its presence and not weighted by the frequency of its occurrence. An action point could be coded for the presence of none to multiple elements of a dimension (column) of the ontology. Thus, an action point may contain elements from one to all the dimensions.

Four teams, comprising two members each, coded the action points. The action points were divided by chapters of NCAP 2019 across the four teams. The coding was by consensus between each pair of team members. There were two iterations. After the first iteration by each team, the process and criteria were discussed by the eight members and project leaders as a group. In the second iteration, each team revised the coding based on group discussions. The coding was finalized after the second group discussion of the second iteration.

\section{Analysis and results}

\section{Monads map}

The monads map numerically and visually summarize the frequency of occurrence of each dimension and element of the ontology in the 198 action points (Figure 2). An MS Excel tool was used to generate the monads map. The number adjacent to the name of the dimension and element is the frequency of its occurrence. The bar below each element is proportional to the frequency relative to the maximum frequency among all elements. Since an action item can be coded to multiple elements of a dimension, the sum of frequencies of elements in a dimension may exceed 198 . The sum may also exceed the frequency of occurrence of the dimension.

The dominant focus of the action items is on the instruments of NCAP 2019, their impetus, level, and location of air pollution. The secondary focus is on the stage and sources of air pollution, and the tertiary focus is on the attributes of air pollution and its impact. The dimensions of air pollution management that are emphasized and those that are not - both presence and absence provide insights. Similarly, the elements of each dimension, especially the dominant dimensions that are emphasized and those which are not. For example, regulatory and information instruments are emphasized to the exclusion of other instruments.

\section{Themes map}

The themes map summarizes the co-occurrence of the ontology elements in the 198 action items (Figure 3). 


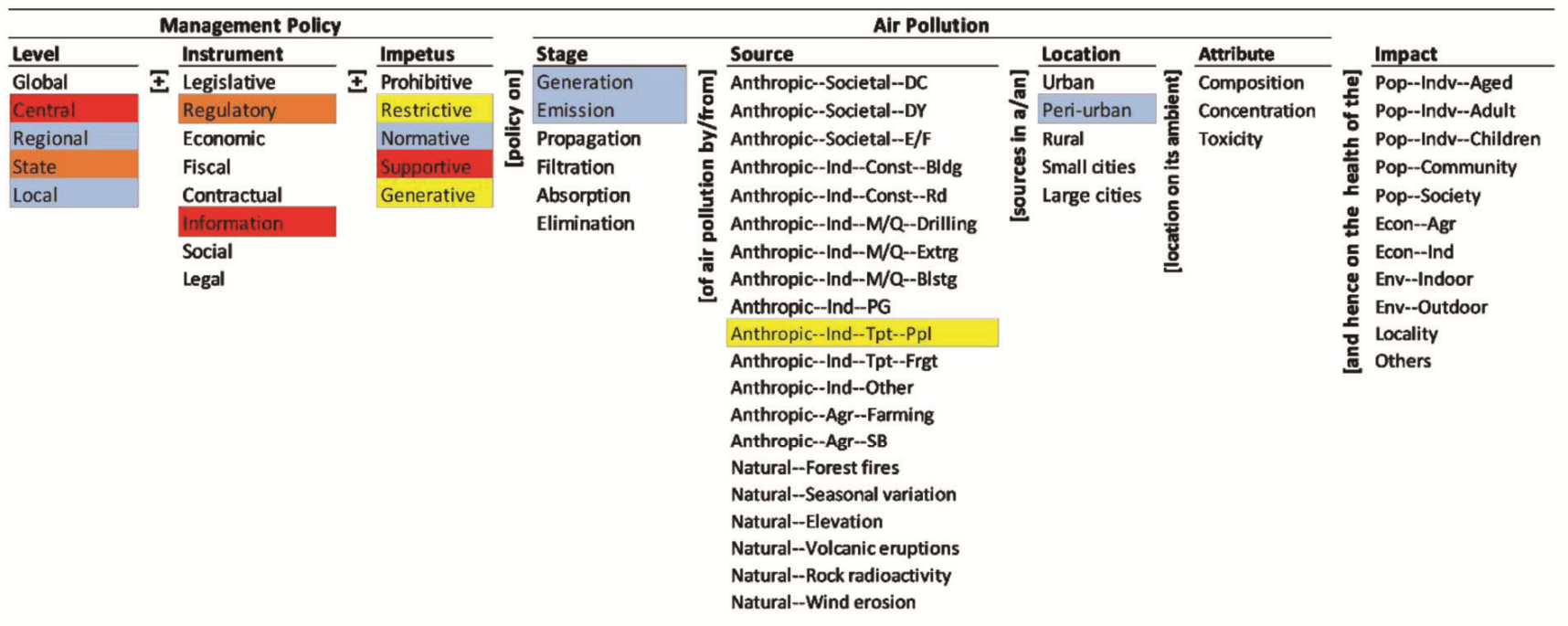

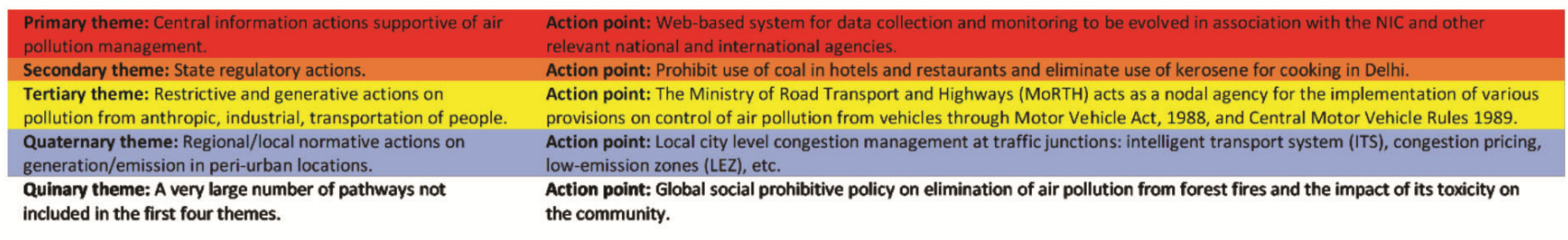

Figure 3. Themes map of NCAP 2019.

The elements of the ontology were clustered based on the similarity of their presence/absence in all the action items. SPSS was used for the cluster analysis with simple matching coefficient $(\mathrm{SMC})^{10}$ as the distance measure, and the nearest-neighbor aggregation procedure. SMC is a symmetric similarity measure which considers presence and absence of the elements equally and provides more consistent comparison across pairs of elements ${ }^{11}$. Five equally spaced clusters were derived from the dendrogram. They were labelled as primary, secondary, tertiary, quaternary and quinary clusters respectively. The five clusters were visually represented by the corresponding colour-coded elements in the ontology - red, orange, yellow, blue and no colour (Figure 3). The themes formed by the concatenation of elements in the five clusters were labelled as primary, secondary, tertiary, quaternary and quinary, and correspondingly coloured below the ontology. An example of the action point corresponding to each theme from NCAP 2019 is shown to the right of each theme (Figure 3).

The themes map highlights the selectivity of action items and their segmentation. A small number of select elements is included in the first four themes. Most of the elements belong to the quinary (absent) theme. No attribute of pollution or type of impact is part of the first four themes. Further, none of these themes encompass all the dimensions - they are fragments of pathways to air pollution management, not complete pathways.

\section{Discussion}

We discuss the results of monads map and themes map. In both, we describe the consequences of inclusion and exclusion of dimensions and elements of the ontology.

\section{Monads}

NCAP 2019 prescribes actions for reducing air pollution at the city and regional levels in India ${ }^{9}$. Among its 198 action items, only a few have explicit outcomes while others may have implicit outcomes. Action items without specified outcomes and their absence limits our understanding of the purpose of the item. It also hinders assessment of the fulfilment of the item. The outcomes of action items must be made explicit.

A report by the Health Effects Institute indicates that air pollution was responsible for 1.1 million deaths in India in 2015 (ref. 12). The risk of death faced by the population in urban and non-urban regions is similar due to pollution by particulate matter $\left(\mathrm{PM}_{2.5}\right)^{13}$. For young families who are an increasing part of the Indian middle class, the location of a prospective home hinges on the level of air pollution in addition to factors such as connectivity and proximity to schools. This is not surprising considering that asthma, stunted lungs, low birthweight and premature deaths are some of the effects in babies and children which are linked with air pollution ${ }^{14}$. 
The aim of NCAP 2019 is to 'gradually improve the air quality and meet the prescribed ambient air quality standards at all locations in the country in the stipulated time

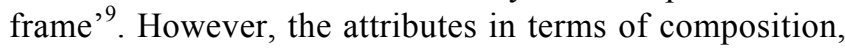
concentration and toxicity of air pollution have been given little emphasis in NCAP 2019, and there is no emphasis on toxicity. It is the attributes of pollution and their accurate estimates of human exposure that determine the type and magnitude of impact ${ }^{15}$. The low emphasis on attributes of pollution appears to be correlated with that on its impact. Significantly though, the location of air pollution is emphasized, but biased. While pollution in urban cities, small and large, is a major concern nationally, the fact that in peri-urban and rural areas it is less emphasized is a matter of concern. The composition, concentration and toxicity of pollutants and their impacts in the latter locations could be quite different from those in the former. The nonlinear linkage between pollution levels and health impact terms of exposure and response calls for different types of actions ${ }^{16}$.

Vehicles, industries, rampant construction, biomass burning, diesel gensets and commercial and domestic use of fuels are recognized as the major anthropic sources of air pollution, with the 'valley effect' and dry alluvial soil significantly contributing to wind-blown dust in the Indo Gangetic Plain ${ }^{9}$. A report by The Energy and Resources Institute ranks emissions at the national scale with industrial $(36 \%)$ and residential combustion (39\%) sectors at the top of the list ${ }^{17}$. Though transport is at $4 \%$, with urban areas having a higher concentration, NCAP 2019 appears to be urban transportation-centric in its approach, and not comprehensive with almost no emphasis on other natural and anthropic sources of air pollution (Figure 2). Moreover, the profile of sources (and consequently the attributes of pollution on its impact) is likely to be different for other locations as the ground-based sources are also found to be contributing more to prevailing air-quality levels. Open burning of agricultural residues in rural areas contributes about $7 \%$ to the total emissions, while cumulatively, the other sectors contribute $11 \%$ (ref. 17).

The emphasis on the stage of air pollution is significant, but not dominant. NCAP 2019 emphasizes actions distributed across mitigation, knowledge-base augmentation, institutional strengthening ${ }^{9}$, and among the stages, the predominant focus is on generation and emission, not on propagation, filtration, absorption and elimination of pollution. The profile fits the urban-transportation schema; it fails to cover the other sources, locations, attributes and impacts discussed earlier.

Contrary to the expectations of a government programme, the dominant impetus is supportive, and the secondary impetuses are restrictive, generative and normative. Prohibitive impetus is tertiary. NCAP 2019 appears to have adopted a positively reinforcing approach to air pollution management, rather than a negatively reinforcing one.
The instruments of policy are dominantly informational and regulatory, not legislative, economic, social, legal or contractual. Positively reinforcing regulation through information appears to be a core logic of NCAP 2019. The policy instruments envisage a dominant combination of Central, State and local interventions. Global and regional interventions are secondary.

\section{Themes}

At a general level, the themes map illustrates both the selectivity (of elements) and segmentation (of dimensions) in the action items. The selectivity of elements has been discussed in the previous section on monads. When considered in combination with other elements, the selectivity is even more pronounced in the themes map. The segmentation of themes highlights the absence of a comprehensive approach to the construction of action items. While it is implicit in the very low emphasis on elements of some dimensions (for example, attributes and impact), it is made explicit by the themes.

The primary theme of NCAP 2019 is the management of air pollution - a complex issue that is emerging as a prominent social problem. Tackling air pollution requires addressing other significant interlinked verticals, including its stage, source, location, attribute and impact. A recent study on managing air quality in mega-cities proposes a multipronged approach taking into account global quality standards, sources, emissions, concentration of particulate matter and health impacts at both national and state levels in India ${ }^{18}$.

The secondary theme is too narrowly focused on the level and instrument of management policy. However, policy instruments need to be in conjunction with impetus such as prohibition or norms as well as stages such as propagation that enhances the effectiveness of policies. The study emphasizes the setting of regulatory standards for multiple pollutants and simultaneously implementing compliance with regulatory standards for the pollutants ${ }^{19}$.

The tertiary theme is narrowly focused on the impetus and the source. Still, it fails to recognize air-quality attributes, location and impact that have been cited as significant in recent years. A study by Lawrence and Fatima ${ }^{20}$ indicated that concentrations of $\mathrm{CO}_{2}, \mathrm{CO}, \mathrm{PM}_{10}$, $\mathrm{PM}_{2.5}, \mathrm{SO}_{2}$ and $\mathrm{NO}_{2}$ above permissible limits impacted the respiratory health of urban residents of Lucknow, Uttar Pradesh, India ${ }^{20}$.

The quaternary theme is slightly broader, but does not consider the sources, attributes and impact of air pollution. In addressing the broader context of setting norms to tackle emissions at local levels, its inadequacy is apparent in referring to levels of toxicity, sources, stage, concentration and impact that are significant elements, as has been found in a recent study on air quality in Bengaluru, Karnataka, India ${ }^{21}$. 
Management policy: Policy to manage air pollution

Level: Intervention level to manage air pollution

Global: Global intervention

Central: Central Government intervention

Regional: Regional Government's interventions

State: State Government's interventions

Local: Local Government's interventions

Instrument: Government intervention to manage air pollution

Legislative: Legislative means

Regulatory: Regulatory methods

Economic: Economic incentives/penalties

Fiscal: Fiscal measures

Contractual: Licensing/contracts

Information: Informational means to manage air pollution

Social: Popularly practised social norms

Legal: Laws

Impetus: Nature of the policy

Prohibitive: A forbidding policy

Restrictive: A restraining policy

Normative: Policy conforming to the norms

Supportive: Policy that can assist or aid

Generative: Policy capable of producing or creating

Air pollution: High concentration of air pollutant in air

Stage: Ways in which air pollutants operate

Generation: Generation of air pollutants

Emission: Air pollutants discharged into the atmosphere

Propagation: Transmission of air pollutants through a medium

Filtration: Removal of air pollutants of different sizes

Absorption: Passage of one substance into or through another

Elimination: Complete removal of air pollutants

Source: Any process, activity or mechanism that releases air pollutants into the atmosphere

Anthropic: From human activities

Societal: From social activities

Domestic cooking: From biofuel burning

Dump yard: From disposal of waste

Events/festival: Due to events or festivals

Industrial: From industrial activities and processes

Construction: From the construction industry

Building: Due to building construction

Road: Due to road construction

Mining/quarrying: From mining quarrying activities

Drilling: From drilling

Extracting: From extracting

Blasting: From blasting

Power generation: From power generation industry

Transportation: From air, water and land transportation

People: Air pollution from transportation of people

Freight: From freight transportation

Other: Other than already mentioned anthropic source

Agriculture: From agriculture

Farming: From farming activities

Stubble burning: From burning of agricultural stubble

Natural: From natural events

Forest fire: From forest fires

Seasonal variation: From change in season

Elevation: Due to elevation

Volcanic eruption: From volcanic activity

Rock radioactivity: From radioactive decay of rocks

Wind erosion: Due to wind erosion

Location: Locality affected by air pollution

Urban: Urban areas affected

Peri-urban: Suburban/semi-urban areas affected

Rural: Rural areas affected 


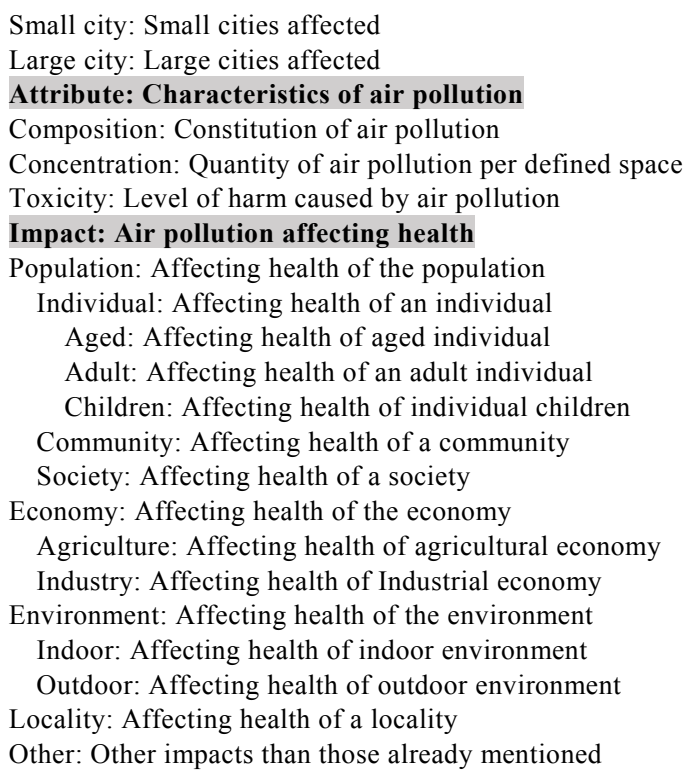

The quinary theme encompasses a large number of pathways that have been overlooked in NCAP 2019. For instance, there is no reference to global health standards, social instruments, sources, composition and impact on people. The importance of these is highlighted in a recent study in India at subnational levels analysing indoor and outdoor air pollution and its large impact on life expec$\operatorname{tancy}^{22}$.

Overall, the themes map illustrates the strong linkages among dimensions of air pollution that are not adequately addressed in NCAP 2019. It fails to highlight the strong evidence existing on daily pollutant concentration levels and variance in the composition of toxic air quality which has differential and combined impacts.

\section{Conclusion}

The ontological analysis of the 198 action items of NCAP 2019 highlights the frequently emphasized, infrequently emphasized and overlooked pathways to manage air pollution in India. The pathways are selective and segmented, not inclusive, and integrated. An ontological review of the state-of-the-research, -policies and -practices can highlight: (a) novel pathways for managing air pollution and (b) roadmaps for research, policies and practices to identify the novel pathways. The reviews and roadmaps can form the basis of evidence-based decisions for managing air pollution in India through an academia government-industry partnership, viz. the triple-helix partnership ${ }^{23}$.

1. Malone, D. W., Modeling air pollution control as a large scale, complex system. Socioecon. Plann. Sci., 1972, 6, 69-85.
2. Ganguli, A., Addressing the challenge of air pollution in India, World Health Organization, Geneva, 2015.

3. Ramaprasad, A. and Syn, T., Ontological meta - analysis and synthesis. Commun. Assoc. Inf. Syst., 2015, 37, 138-153.

4. Ramaprasad, A. and Syn, T., Design thinking and evaluation using an ontology. In Design Science: Perspectives from Europe (eds Helfert, M., Donnellan, B. and Kenneally, J.), Springer, Cham, 2014, pp. 63-74.

5. Cameron, J. D., Ramaprasad, A. and Syn, T., An ontology of and roadmap for mHealth research. Int. J. Med. Inf., 2017, 100, 16-25.

6. Ramaprasad, A., Singai, C. B., Hasan, T., Syn, T. and Thirumalai, M., India's National Higher Education Policy recommendations since independence: an ontological analysis. J. Educ. Plann. Admin., 2016, 30, 5-24.

7. Mondaca, A. N., Ramaprasad, A. and Syn, T., National healthcare policies in Chile: an ontological meta-analysis. In eHealth-enabled Health (eds Sarkar, I. N., Georgiou, A. and Marques, P. M. de A.), Studies in Health Technology and Informatics, São Paulo, Brazil, 2015, pp. 1105-1105.

8. Lascoumes, P. and Le Gales, P., Introduction: understanding public policy through its instruments - from the nature of instruments to the sociology of public policy instrumentation. Governance, 2007, 20, 1-21.

9. MoEF, National Clean Air Programme, Ministry of Environment, Forest \& Climate Change, Government of India, 2019, p. 106.

10. Sokal, R. R. and Michener, C. D., A statistical method for evaluating systematic relationships, University of Kansas, Lawrence, Kan, 1958.

11. Syn, T. and Ramaprasad, A., Megaprojects - symbolic and sublime: an ontological review. Int. J. Manage. Proj. Business, 2019, 12, 377-399.

12. Health Effects Institute, HEI 2018 Annual Report. HEI, Boston, MA, USA, 2018.

13. Ravishankara, A. R., David, L., Pierce, J. and Venkataraman, C., Outdoor air pollution in India is not only an urban problem. Proc. Natl. Acad. Sci. USA, 2020, 117(46).

14. Carrington, D., Location, location, lung disease: pollution ads target property market. The Guardian, 2019.

15. Ghio, A. J., Carraway, M. S. and Madden, M. C., Composition of air pollution particles and oxidative stress in cells, tissues, and 
living systems. J. Toxicol. Environ. Health Part B, 2012, 15, $1-21$.

16. Carlsten, C., Salvi, S., Wong, G. W. K. and Chung, K. F., Personal strategies to minimise effects of air pollution on respiratory health: advice for providers, patients and the public. Eur. Respir. $J ., 2020,55$.

17. Sharma, S. and Kumar, A. (eds), Air Pollutant Emissions Scenario for India, The Energy and Resources Institute, New Delhi, 2016.

18. Amann, M. et al., Managing future air quality in megacities: a case study for Delhi. Atmos. Environ., 2017, 161, 99-111.

19. Dominici, F., Peng, R. D., Barr, C. D. and Bell, M. L., Protecting human health from air pollution: shifting from a single-pollutant to a multi-pollutant approach. Epidemiology, 2010, 21, 187-194.

20. Lawrence, A. and Fatima, N., Urban air pollution and its assessment in Lucknow city - the second largest city of North India. Sci. Total Environ., 2014, 488-489, 447-455.

21. Guttikunda, S. K. et al., Air quality, emissions, and source contributions analysis for the Greater Bengaluru region of India. Atmos. Pollut. Res., 2019, 10, 941-953.
22. Balakrishnan, K. et al., The impact of air pollution on deaths, disease burden, and life expectancy across the states of India: The Global Burden of Disease Study 2017. Lancet Planet. Health, 2019, 3, e26-e39.

23. Etzkowitz, H. and Zhou, C., The Triple Helix: UniversityIndustry-Government Innovation and Enterpreneurship, Routledge and CRC Press, London, 2018.

ACKNOWLEDGEMENT. Apoorva Arvind Kumar and Poornima K. Wasdani helped formulate the initial version of the ontology used in this manuscript.

Received 4 November 2019; revised accepted 14 December 2020

doi: $10.18520 / \mathrm{cs} / \mathrm{v} 120 / \mathrm{i} 8 / 1295-1302$ 